 REVISTA CIENTIFICA ELETRÓNICA DE ENGENHARIA DE PRODUÇÃO
}

\section{ANÁLISE DE MERCADO E NÍVEL DE CONCENTRAÇÃO DA INDÚSTRIA DE PAPEL TISSUE NO BRASIL}

\section{MARKET ANALYSIS AND CONCENTRATION LEVEL OF THE TISSUE PAPER INDUSTRY IN BRAZIL}

\author{
Sebastião Décio Coimbra de Souza* E-mail: decio.coimbra@yahoo.com.br \\ Samilla Lima Bastos* E-mail: samillabastos@gmail.com \\ *Universidade Estadual do Norte Fluminense (UENF)/ Centro de Ciência e Tecnologia (CCT) Lab Eng de \\ Produção, Campos dos Goitacazes, RJ
}

Resumo: O objetivo dessa pesquisa foi avaliar o nível de concentração do mercado brasileiro de papéis tissue e analisar seus reflexos em termos de desempenho relativo por linha de produto. Papéis tissue, ou papéis sanitários, compõem um segmento que abrange a produção de uma linha bastante variada de produtos, incluindo desde papel higiênico, papel toalha até fraldas e lenços para bebês, cujas características mais aparentes são maciez e textura aveludada, constituindo-se em um nicho de mercado diferenciado. A participação do segmento tissue na produção total de papéis no Brasil tem apresentado crescimento constante nos últimos anos, e estudos prospectivos do setor indicam que esse indicador deve se manter acima de $4 \%$ ao ano até 2020. A pesquisa foi exploratória e descritiva, com abordagem mista, sendo parte qualitativa, com a abordagem do método interpretativo EstruturaConduta-Desempenho (ECD), e parte quantitativa, com o cálculo dos índices de concentração de mercado, e a estratificação da linha de produtos. De forma geral, os resultados mostraram que o segmento apresenta uma estrutura industrial de baixa concentração de mercado, tendência que tem se consolidado nos últimos anos. Através dos resultados foi possível concluir que devido à forte concorrência no segmento, com diferenciação de itens por linha de produtos, o mix de tecnologias de processo, e o foco em eficiência operacional e na redução de custos, condicionam os padrões de conduta e as estratégias de produção, o que permitiu a introdução de novos produtos, de melhor qualidade, sem que houvesse aumentos de preços significativos. Essa configuração de fatores é a característica mais importante para sustentar a tendência de crescimento desse segmento industrial.

Palavras-chave: Papel Tissue. Organização Industrial. Dinâmica Industrial. Modelo ECD. Índice de Concentração.

\begin{abstract}
The study evaluates the level of concentration of the Brazilian tissue paper market and analyzes its reflexes in terms of relative performance by product line. Tissue papers, or sanitary papers, comprise a segment that covers the production of a very varied line of products, from toilet paper, towel paper to diapers and baby wipes, whose most apparent characteristics are softness and velvety texture, constituting a niche. Tissue segment participation in total paper production in Brazil has been growing steadily in recent years and prospective studies indicate that domestic production of this segment should remain above $4 \%$ per year by 2020 , despite recent macroeconomic difficulties in the country. The research was exploratory and descriptive, with a mixed approach, being part qualitative, with the approach of the interpretive method Structure-Conduct-Performance (SCP), and quantitative part, in which it calculated the market concentration indices, with the stratification of the product line. Overall, the results showed that the segment has an industrial structure with a low market concentration, a tendency that has consolidated in recent years. In summary, the results allowed concluding that due to the strong competition with the differentiation of items by product line, the mix of process technologies and the focus on operational efficiency and cost reduction; condition the conduct patterns and the production strategy, which allowed the introduction of new and better quality products without significant price increases. This configuration of factors is the most important characteristic to sustain the growth trend of this industrial segment.
\end{abstract}


Keywords: Tissue paper. Industrial organization. Industrial dynamics. SCP model. Concentration index.

\section{INTRODUÇÃO}

Papéis tissue são papéis sanitários, aqueles que compõem folhas ou rolos de baixa gramatura, usados para higiene pessoal e limpeza doméstica, como papel higiênico, lenços, papel-toalha, toalhas de mão e guardanapos. Entretanto o segmento tissue não se restringe à fabricação de papéis, engloba uma ampla variedade de outros produtos, como fraldas e absorventes femininos e constitui uma indústria de recursos e mercados diversificados que permitem variedade na produção (BRACELPA, 2016).

Os papéis tissue recebem esse nome devido as suas propriedades físicas que são similares às de um tecido, como suavidade, espessura, resistência e capacidade de absorção de umidade. Tais propriedades são adquiridas devido às características de processamento de fibras de baixa gramatura $\left(14\right.$ a $\left.50 \mathrm{~g} / \mathrm{m}^{2}\right)$ e produção preferencial com fibras curtas, o que lhes confere a maciez característica, permitindo ao fabricante utilizar alternativamente fibras recicladas. Baixas gramaturas são usadas em produtos de multicamadas onde a maciez é importante, como lenços faciais e fraldas (SARAIVA e CAPO, 2003; MILANEZ e HOST, 2005).

A participação de papéis tissue na produção total de papéis no Brasil, segundo a Indústria Brasileira de Árvores (IBA), passou de 8,3\% em 2000 para 11,8\% em 2014, e conforme levantamento realizado pela Pöyry, multinacional finlandesa de consultoria e serviços de engenharia, aponta que a produção nacional de papéis tissue deve crescer a taxas anuais de 4\% até 2020, acima dos 3\% registrados entre 2004 e 2014 (PÖYRY, 2015).

Atualmente há 13 fabricantes no Brasil que utilizam exclusivamente ou quase exclusivamente polpa reciclada, e 14 que utilizam apenas pasta química, sendo que os demais utilizam uma mistura de pasta reciclada e química (O PAPEL, 2015a).

Esse trabalho explora um segmento raramente presente na literatura acadêmica na área de Engenharia de Produção, e em especial, no tocante ao mercado e à organização industrial. Nesse sentido, o artigo visa contribuir para o entendimento das características desse mercado de produtos tão presentes no dia a dia e essencialmente importantes para a qualidade de vida das pessoas, além de 
fornecer informações estratégicas sobre uma indústria de grande potencial de crescimento para o país (VIDAL e HORA, 2013; BASTOS e SOUZA, 2016).

Para o estudo e entendimento dos mercados e da organização das indústrias, um dos métodos mais utilizados é o modelo analítico Estrutura-Conduta-Desempenho (ECD), devido à sua abrangência, simplicidade e possibilidades de aplicações. $O$ modelo ECD visa organizar os pontos chaves para uma análise de mercado de modo a preparar uma empresa para os desafios econômicos que ela irá enfrentar, colocando de forma sistemática e articulada os principais fatores, os variados desafios para análise da indústria e as eventuais barreiras de mercado, através de uma perspectiva histórica e busca apontar tendências de fatores e variáveis estratégicas (SCHERER e ROSS, 1990; CARLTON e PERLOFF, 1994; WIRTH e BLOCK,1995).

O objetivo desse artigo é apresentar uma análise da estrutura do setor, o desempenho e as características do mercado de papel tissue, os principais fabricantes e o grau de concentração desse segmento de mercado no Brasil. Para tanto, o trabalho apoia-se nos aspectos teóricos da organização industrial e de mercados, com aplicação do modelo ECD. O trabalho está dividido da seguinte forma: $O$ item 2 apresenta um panorama do segmento de papéis tissue no Brasil. O tópico 3 apresenta o modelo ECD, seus fundamentos e variáveis consideradas, incluindo os métodos adotados como medidas do nível de concentração de mercado. $O$ item 4 descreve a metodologia utilizada para realização do trabalho, enquanto o tópico 5 mostra os resultados da aplicação do modelo ECD no segmento tissue no Brasil. Por fim, no item 6 , são apresentadas as conclusões, com as considerações mais relevantes, seguido das referências utilizadas.

\section{PANORAMA DO MERCADO DO SEGMENTO TISSUE NO BRASIL}

O Brasil é o 5o país em termos de capacidade instalada para produção de tissue, atrás apenas da China, EUA (juntos representam 44\% da produção mundial), Japão e Itália e com uma produção muito próxima desses dois últimos. Esses cinco países respondem atualmente por $59 \%$ da produção mundial de tissue (PÖYRY, 2016). O mercado tissue é um dos segmentos da indústria de papel e celulose.

Da produção total de papel do Brasil, 53\% são para embalagens, 24\% para de papeis de imprimir e escrever, e $11 \%$ são representados pelo segmento tissue (IBA, 
2015). Os demais segmentos da indústria de papeis no Brasil são representados por Cartões, Papeis especiais e outros, e Jornais. A Figura 1, a seguir, mostra a distribuição percentual da produção brasileira por segmento de mercado de 2000 a 2015.

Figura 1 - Distribuição percentual da produção por segmento de papel no Brasil

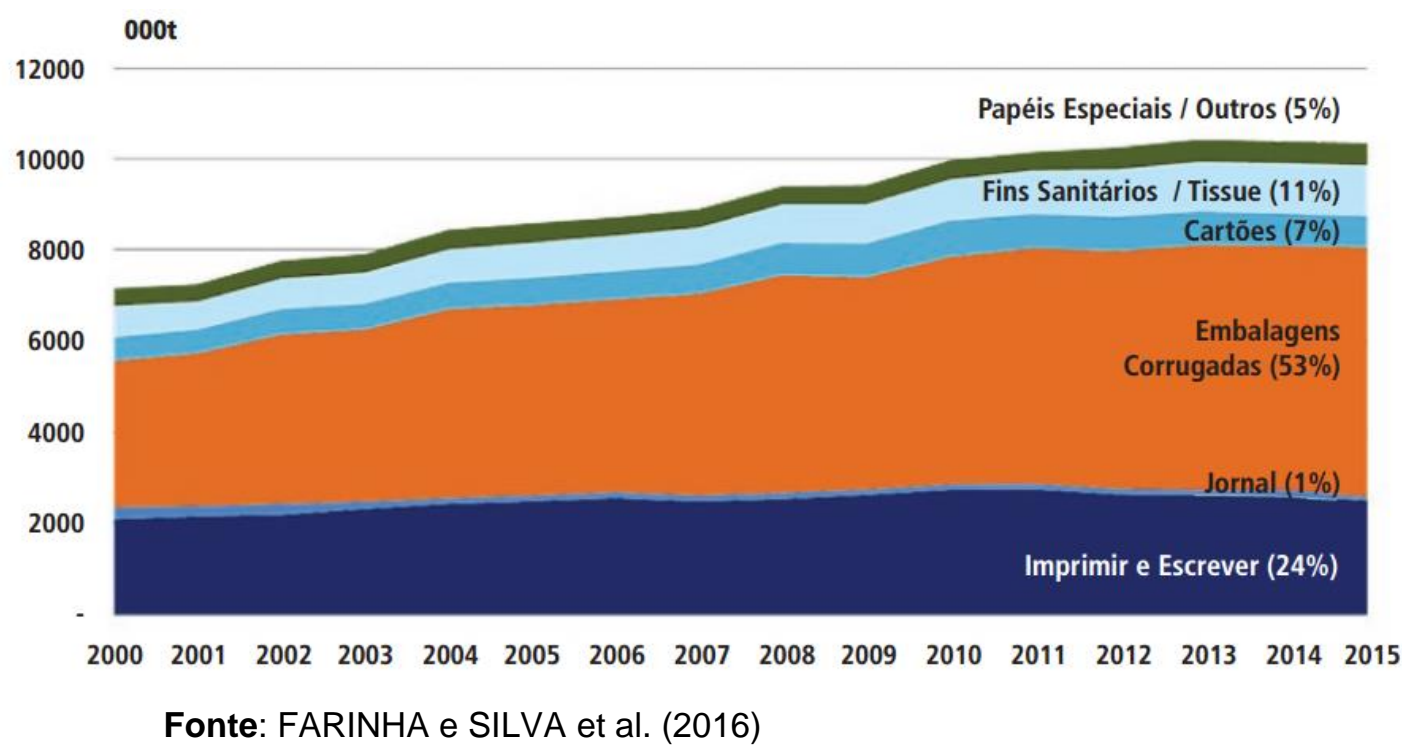

No caso da celulose, grande parte da produção, acima de $70 \%$, tem como matéria prima o eucalipto, e o restante utilizam pinus e outras fontes. A maior parte da produção de celulose brasileira, aproximadamente $67 \%$, tem como destino o mercado externo, com apenas 33\% da produção destinadas ao mercado doméstico (IBA, 2016). Do total de celulose produzida, em torno de $86 \%$ é do tipo fibra curta, que é a matéria prima básica da indústria tissue.

A fibra curta tem maior capacidade de absorção e destina-se à fabricação de produtos menos rígidos, como papeis de impressão, para escrever e papéis tissue. A fibra longa proporciona maior resistência ao material e por isso é uma matéria prima básica na fabricação de embalagens.

No Brasil, segundo Vital (2008), o primeiro papel higiênico foi introduzido em 1928, pela Companhia Melhoramentos, que na época usava o nome de fantasia "Sul América". A mesma empresa introduziu também as toalhas de papel "Volga", que eram vendidas principalmente para barbearias.

Na década de 1950, caracterizada pelo forte crescimento industrial do Brasil, o investimento industrial foi incentivado e a produção de papel teve um salto de 5,7 mil 
para 20 mil toneladas. Neste período foram construídas grandes fábricas de papel no país, como por exemplo a Klabin e a Santher (VITAL, 2008).

Nos anos seguintes o mercado brasileiro se mostrou em constante ascensão e bastante atrativo. Novos fornecedores surgiram, novas empresas se instalaram e algumas empresas realizaram fusões e incorporações. A instalação das empresas e concentração geográfica ocorreu notadamente nas regiões de maior demanda e de mercados maiores, como São Paulo, Minas e Rio de Janeiro (VIDAL e HORA, 2013).

O Brasil é o maior produtor mundial de celulose de fibra curta, em grande parte favorecido pelo clima tropical que proporciona condições ideais para o plantio de eucalipto, principal matéria prima para esse tipo de fibra.

Segundo Farinha e Silva et al. (2016), no período compreendido entre os anos de 2000 a 2015, a produção de papeis no Brasil cresceu acima do PIB nacional, acompanhando o crescimento da demanda no mercado doméstico. Nos últimos dez anos, o maior destaque de crescimento na indústria brasileira de papeis ficou por conta dos segmentos de embalagem e de tissue. A Tabela 1 mostra a produção nos anos de 2000, 2013 e 2015, e o crescimento médio anual, por segmento, da indústria de papeis no Brasil. O segmento tissue apresentou uma taxa de 3,2\% de crescimento médio anual, acima da média do setor, que foi de $2,5 \%$.

\begin{tabular}{|l|c|c|c|c|}
\hline Tabela 1 - Produção por tipo de papel e crescimento médio anual \\
\hline Papel & $\mathbf{2 0 0 0}$ & $\mathbf{2 0 1 3}$ & $\mathbf{2 0 1 5}$ & $\begin{array}{c}\text { Crescimento } \\
\text { médio /a.a. } \\
\text { (\%) }\end{array}$ \\
\hline Embalagem PO & 3.209 & 5.373 & 5.471 & $3,6 \%$ \\
Imprimir e Escrever & 2.093 & 2.616 & 2.492 & $1,2 \%$ \\
Jornal & 266 & 105 & 98 & $-6,4 \%$ \\
Cartões & 519 & 702 & 691 & $1,9 \%$ \\
Fins Sanitários/Tissue & 697 & 1.122 & 1.114 & $3,2 \%$ \\
Papéis Especiais & 378 & 479 & 491 & $1,8 \%$ \\
\hline Total & $\mathbf{7 . 1 6 2}$ & $\mathbf{1 0 . 3 9 7}$ & $\mathbf{1 0 . 3 5 7}$ & $\mathbf{2 , 5 \%}$ \\
\hline
\end{tabular}

Fonte: FARINHA e SILVA et al. (2016)

A demanda de papeis sanitários no país aumentou 38\% entre 2005 e 2015. Nesse período, o consumo per capita cresceu de 3,9kg para 5,4kg em 2016. Apesar disso, em comparação com outros países em desenvolvimento, o consumo brasileiro de papeis tissue ainda é baixo, mesmo no contexto da América Latina, onde Argentina 
Chile, México, e inclusive a Venezuela, apresentam consumo per capita maior que o Brasil (PÖYRY, 2016).

Apesar da crise econômica que assolou o país nos três últimos anos, que provocou um pequeno decréscimo registrado de 2014 para 2015, a projeção é de crescimento de demanda entre 1 a 2 pontos percentuais acima do PIB no médio e longo prazos (PÖYRY, 2016).

A participação do tissue frente à produção total de papel no país passou de 8,3\% em 2000 para 11,8\% em 2014, e mesmo com a forte queda do PIB brasileiro de $3,8 \%$ em 2015, manteve-se nesse patamar, com leve queda para 11,6\%, segundo dados da Anguti Estatística (FARINHA et al. 2016; IBA, 2016).

Atualmente, o mercado brasileiro é dominado por quatro grandes empresas que detém cerca de 50\% da participação (BASTOS e SOUZA, 2016). A Figura 2 apresenta a distribuição do mercado no país.

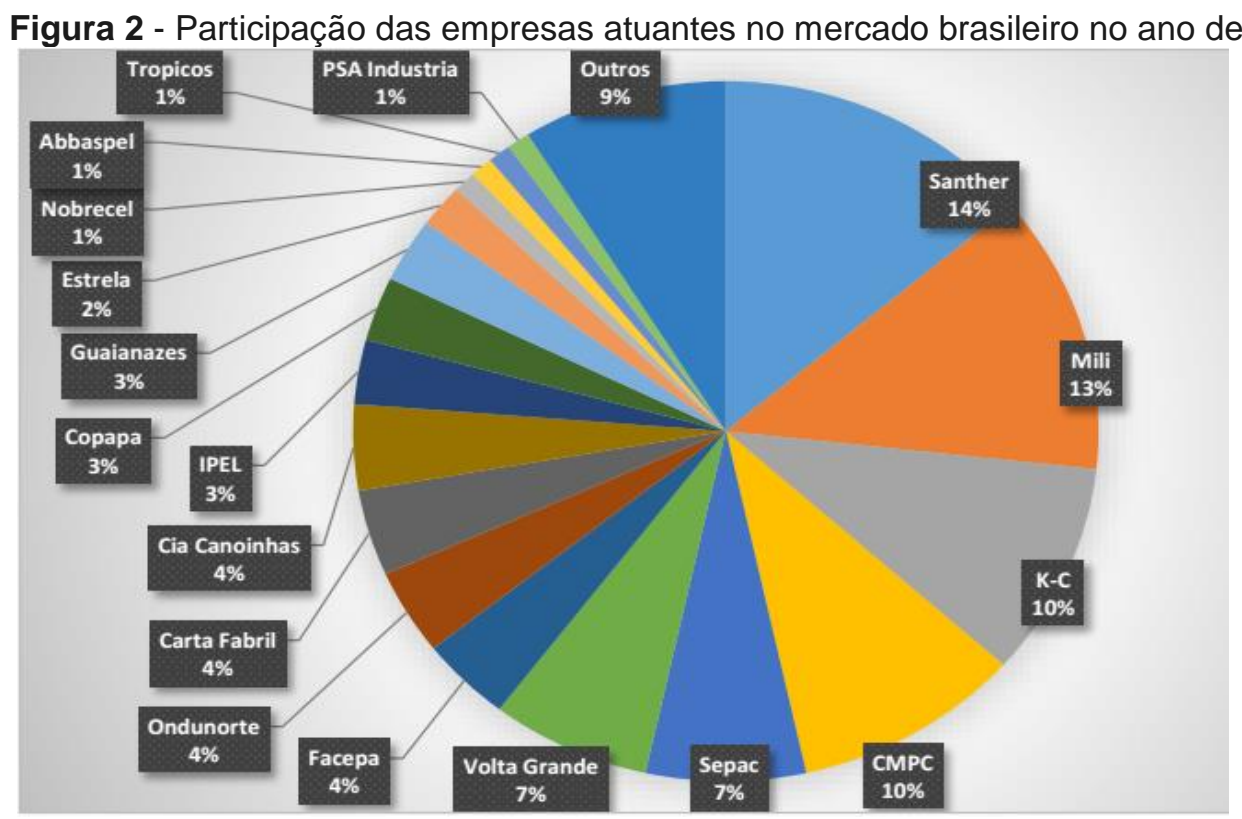

Fonte: O PAPEL (2015a)

\section{O MODELO ESTRUTURA-CONDUTA-DESEMPENHO (ECD)}

Segundo Scherer e Ross (1990), a função principal do modelo ECD é permitir o estudo de mercado através das variáveis que influenciam no desempenho econômico, permitindo análises das condições básicas da indústria, das condutas 
práticas e estratégicas adotadas pelas firmas concorrentes e o desempenho no mercado.

Em sua formulação original, o modelo ECD concebia um encadeamento causal das condições básicas de oferta e demanda para a configuração da estrutura de mercado e reflexos nos preços, nos resultados das empresas e no desempenho econômico setorial (WIRTH e BLOCK,1995; LIPCZYINSKI et al. 2009). As relações entre os elementos e algumas variáveis consideradas nesse modelo são ilustradas resumidamente na Figura 3, a seguir, e descritos nas seções adiante.

Figura 3 - O modelo ECD simplificado, seus elementos básicos e principais variáveis



Fonte: RIBEIRO et al. (2013)

Desde sua proposição nos anos 1930, por Edward Mason (MASON, 1939, apud LIPCZYINSKI et al. 2009), e posterior aprofundamento em seus fatores, por Joe Bain (ver BAIN, 1968, apud CHURCH e WARE, 2000), o modelo ECD tem sido amplamente empregado na literatura sobre organização industrial. No entanto, a partir de estudos dos anos 1970 e 1980, com as mudanças políticas que provocaram mudanças profundas no mercado internacional e na política industrial de diversos países, a tradicional teoria neoclássica de equilíbrio geral de preços passou a ser contestada (CARLTON e PERLOFF, 1994).

Nesse contexto, o modelo ECD, na sua versão original, passou a ter sua aplicabilidade questionada, e alguns de seus postulados passaram a sofrer críticas, basicamente devido à premissa endógena de causalidade linear entre os fatores considerados e pela não consideração da dinâmica do ambiente e efeitos exógenos, 
o que levou à proposição de versões aperfeiçoadas com a incorporação de fatores dinâmicos ao modelo original (SCHERER e ROSS, 1990; CHURCH e WARE, 2000; LIPCZYINSKI et al. 2009, DAl et al,, 2017). Abordagens alternativas passaram a adotar elementos do modelo sob hipóteses dinâmicas e evolucionárias (ALBINO et al., 2011; SOUZA, 2011; GAVETTI et al., 2012).

Nesse trabalho, adotou-se uma perspectiva dinâmica e aplicada do modelo ECD, com análise da variação no nível de concentração do mercado no decorrer do tempo. A seguir são apresentados de forma sintética os fatores principais da abordagem adotada.

\subsection{Estrutura de Mercado}

A estrutura de mercado depende de uma série de condições básicas advindas das relações entre oferta e demanda. A estrutura de mercado está relacionada com as características de organização das indústrias que influenciam a dinâmica competitiva setorial e, por consequência, os preços dentro de um determinado mercado. Logo, a estrutura refere-se à maneira como as empresas que integram uma indústria se organizam e como elas interagem entre si, suas formas de produzir e vender e o seu grau de concentração do mercado ( $\mathrm{CHURCH}$ e WARE, 2000; LIPCZYINSKI et al. 2009; DAl et al., 2017).

Os métodos mais utilizados para se medir a concentração em um mercado são a Razão de Concentração (Cr) e o índice Herfindahl-Hirschman (HH).

A Razão de concentração $(\mathrm{Cr})$ mede a parcela de mercado representada por um número fixo $(\mathrm{k})$ das maiores empresas de um mercado em relação ao total, tomando-se como base o indicador $(k)$ escolhido. O cálculo da razão de concentração é dado por:

$$
\operatorname{Cr}(\mathbf{k})=\sum_{i=1}^{k} P i
$$

Sendo: $\mathrm{k}$ = número de empresas consideradas; $\mathrm{Pi}=$ parcela da capacidade produtiva ou de vendas compartilhadas de cada empresa no mercado. Este índice indica à participação no mercado das $k$ maiores empresas que formam este mercado em específico. 
O Índice de Herfindahl-Hirschman $(\mathrm{HH})$ é similar à razão de concentração, porém, é definido pelo somatório dos quadrados da participação percentual de cada empresa em relação ao tamanho total do mercado. Este índice leva em conta todas as empresas do mercado, ou a grande maioria delas, e é calculado pela seguinte fórmula (NAWROCKI e CARTER, 2009; MCAULIFFE, 2014)

$$
\mathbf{H H}=\sum_{i=1}^{n} P i^{2}
$$

Sendo: $\mathrm{n}$ : número de empresas participantes no mercado; Pi: parcela da capacidade produtiva ou de vendas de cada empresa no mercado elevado ao quadrado.

Elevar cada parcela da capacidade produtiva ao quadrado implica atribuir um peso maior às empresas relativamente maiores. Dessa forma, quanto maior for o valor de HH, maior será a concentração então, menor a concorrência entre as empresas (HAUSE, 1977; NAWROCKI e CARTER, 2009).

$\mathrm{O}$ índice $\mathrm{HH}$ baseia-se na participação de cada empresa no total da capacidade de produção do mercado e acaba variando valores entre $1 / n \leq H H \leq 1$. Se $H H=1$ pode-se afirmar que se trata de monopólio de mercado; se $\mathrm{HH}=1 / \mathrm{n}$, as empresas terão a mesma capacidade produtiva ou mesmo percentual de mercado compartilhado. Se $\mathrm{n}$ tender ao infinito, então $\mathrm{HH}$ irá tender a zero, o que representa um mercado em condições de competição perfeita, ou similar.

\subsection{Conduta ou estratégias de mercado}

A conduta está relacionada com as ações e comportamento de mercado, as posturas estratégicas adotadas pelas empresas para enfrentar a concorrência, atender aos clientes e se relacionar com fornecedores e organizações públicas. Compreende práticas e processos de escolha entre diferentes alternativas de decisão quanto às variáveis do ambiente interno e externo. Consiste nas estratégias comerciais que se convertem em característica diferencial da empresa, aquela que a destaca perante o mercado e reflete sua missão, visão, valores e imagem (HENDERSON,1998; GRANT, 1991; PORTER, 1991; CHURCH e WARE, 2000; SOUZA et al., 2010; GAVETTI et al., 2012). 


\subsection{Desempenho de mercado}

O desempenho de mercado é o resultado das vantagens competitivas das empresas e consiste no efeito prático da conduta no mercado. Este, por sua vez, sofre reflexos da estrutura de mercado, das políticas públicas e das condições de oferta e demanda, entre outros. O desempenho considera variáveis medidas ex post facto, ou seja, tais variáveis são medidas apenas após o processo (ação) ter acontecido, e decisões terem sido tomadas (SCHERER e ROSS, 1990; KADIYALI et al., 2001; SOUZA e ARICA, 2006; DAl et al., 2017).

$\mathrm{Na}$ aplicação do modelo ECD, existem diversos aspectos a serem explorados, e cabe aos pesquisadores ou tomadores de decisão considerar os mais relevantes para fins de análise da indústria e mercado escolhido. Entretanto, na avaliação do desempenho industrial, há uma ênfase nos aspectos financeiros e econômicos (COSTA e GARCIAS, 2009).

\section{METODOLOGIA}

A pesquisa foi exploratória e documental, com abordagem mista, sendo parte quantitativa e parte qualitativa. Foi adotado o modelo ECD, com incorporação do cálculo dos índices de concentração $\mathrm{CR}$ e $\mathrm{HH}$. Para cada fator previsto no modelo foram avaliados previamente quais os elementos de maior relevância e influência em termos de competitividade, considerando características e peculiaridades inerentes ao setor. Os elementos avaliados para um dos fatores previstos no modelo adotado foram os seguintes:

- Estrutura: Concentração geográfica do mercado, Barreiras a entrada, Diferenciação do produto;

- Conduta: Propaganda, Pesquisa e Desenvolvimento (P\&D); Preço, qualidade e tecnologia; Aquisições e fusões.

- Desempenho: Crescimento do mercado, Crescimento interno de vendas, Perspectivas para este mercado.

Como fontes de pesquisa, foram coletados dados e informações em publicações do setor, disponíveis à associados, e relatórios fornecidos diretamente aos autores por empresas e entidades setoriais. A pesquisa priorizou informações e 
dados consolidados e publicados, que durante o período de coleta (2015) se restringiam aos anos de 2000, 2006 e 2011. Adicionalmente, informações e dados recentes do setor também foram consideradas na análise, para melhor entendimento do escopo e tendência das variáveis avaliadas.

Para identificação das características e dos números do mercado de papel tissue no Brasil, foi realizado um levantamento prévio dos fatores e variáveis previstos no modelo ECD. Também foram utilizados dados secundários da revista O Papel; dados disponibilizados pela Associação Brasileira de Celulose e Papel (BRACELPA), do portal de divulgação de resultados do mercado de papel tissue no Brasil (tissueonline.com.br), e também relatórios da empresa de engenharia e consultoria finlandesa Pöyry.

A partir dos dados obtidos, foram calculados a Razão de Concentração $\left(C R_{k}\right)$ e o índice de Herfindahl-Hirschman $\left(\mathrm{HH}_{\mathrm{k}}\right)$ considerando na sequência, as quatro maiores empresas no mercado, em seguida as seis maiores; e por fim as nove maiores, para os anos de 2000/2006/2011, respectivamente. Para cada ano, foram consideradas as empresas indicadas a seguir:

- 2000: Klambem-Kimberly (K-C), Santher, Melhoramentos, Manicraft, Mili, Canoinhas, Copapa, Sepac, Nobrecel;

- 2006: Kimberly-Clark (K-C), Santher, Mili, Melhoramentos, Copapa, Sepac, Manicraft, Canoinhas, Nobrecel;

- 2011: Santher, CMPC, Kimberly-Clark (K-C), Mili, Sepac, Facepa, Canoinhas, Carta Fabril, Ondunorte.

A partir dos resultados encontrados efetuou-se uma análise da evolução dos fatores Estrutura, Conduta e Desempenho, considerando os índices $\mathrm{CR}$ e $\mathrm{HH}$ calculados. Em relação ao desempenho, foram considerados as seguintes linhas de produtos tissue: - Papeis sanitários (folha simples de alta qualidade, folha simples de boa qualidade, folha dupla e popular), além de - Toalha de mão/Papel toalha, Guardanapo e, - Lenço. 


\section{RESULTADOS E ANÁLISE DO SEGMENTO DE PAPÉIS TISSUE NO BRASIL À LUZ DO MODELO ECD}

\subsection{Estrutura}

a) Concentração geográfica do mercado: a concentração de um mercado pode ser vista como o pilar de uma estrutura industrial e sua medida pretende oferecer um indicador sintético da concorrência existente em um mercado. $\mathrm{O}$ cálculo dos índices de concentração de mercado assume grande relevância no que tange a avaliação das condições de livre concorrência, oligopólios e monopólios. No caso em questão, a estrutura desse segmento no setor configura-se um oligopólio do tipo diferenciado. A seguir é demonstrada a concentração de empresas por região no país, no ano de 2013.

Tabela 2 - Distribuição por região do Brasil e percentual produzido

\begin{tabular}{lcc}
\hline \multirow{2}{*}{ Região } & No. de Empresas & $\begin{array}{c}\text { Volume produzido } \\
(\boldsymbol{\%})\end{array}$ \\
\hline Sul & 26 & 41 \\
Sudeste & 28 & 45 \\
Norte & 1 & 14 \\
Nordeste & 8 & - \\
Centro Oeste & 1 & - \\
\hline
\end{tabular}

Fonte: Bastos e Souza (2016)

Percebe-se que as empresas se concentram nas regiões Sul e Sudeste, o que se explica pelo fato de serem os maiores mercados consumidores e, consequentemente viabilizarem melhores condições de custos logísticos. Dessa forma, as empresas tendem a se concentrar próximo aos maiores mercados. Há grande disparidade de consumo por região e cidade no Brasil. Por exemplo, enquanto na cidade de São Paulo, capital, o consumo ultrapassa os 15 kg/ano/habitante, em toda a região Nordeste o consumo é de apenas $3,5 \mathrm{~kg} / \mathrm{ano} / \mathrm{habitante,} \mathrm{ou} \mathrm{seja,} \mathrm{o}$ volume consumido apenas na capital paulista é quase cinco vezes maior do que o consumido na região Nordeste. Entretanto, em razão do baixo consumo per capita de papel nas regiões Norte, Nordeste e Centro-Oeste, estas são consideradas mercados 
com grande potencial de crescimento para o setor nos próximos anos (O PAPEL, 2015b; BASTOS e SOUZA, 2016).

É interessante observar que na região Sul se localiza um grande número unidades fabris, 26 empresas, bem próximo das 28 unidades produtoras do Sudeste, região que representa a maior participação da indústria nacional de tissue. Em termos de produção, a diferença é ainda menor: em 2013 o Sudeste concentrou 45\% do volume produzido, contra $41 \%$ no Sul e apenas $14 \%$ na região Norte. Embora existam empresas em todas as áreas do Brasil, a concentração é marcante nessas duas regiões, correspondendo a 86\% da produção nacional (O PAPEL, 2015a).

Por outro lado, apesar da participação das outras regiões do país ainda ser pequena, já se observa considerável perspectivas de aumento, já que algumas empresas, como KC e Mili, divulgaram recentemente planos de negócios prevendo maciços investimentos no Nordeste (O PAPEL, 2015a). A evolução do volume produzido no mercado nacional no período de 2000 a 2011 é mostrada na Tabela 3, a seguir. Apesar dos dados referentes ao período de 2011 a 2016 ainda não estivessem consolidados durante a coleta de dados, foram incluídas considerações a partir de informações e dados específicos obtidos, importantes para entendimento das tendências das variáveis.

\begin{tabular}{|c|c|c|c|}
\hline Ranking & 2000 & 2006 & 2011 \\
\hline 19 & 20,73 & 17,99 & 12,40 \\
\hline $2^{\circ}$ & 17,73 & 14,72 & 10,00 \\
\hline $3^{\circ}$ & 10,05 & 8,31 & 9,80 \\
\hline $4^{\circ}$ & 6,46 & 8,04 & 7,50 \\
\hline $5^{\circ}$ & 4,91 & 3,88 & 5,00 \\
\hline 60 & 2,89 & 3,84 & 4,90 \\
\hline $7^{\circ}$ & 2,83 & 2,99 & 3,40 \\
\hline 80 & 2,71 & 2,73 & 3,20 \\
\hline 9 은 & 1,62 & 2,36 & 2,60 \\
\hline
\end{tabular}

Fonte: O Papel (2015b); Bastos e Souza (2016)

Para fins de análise do grau de concentração do mercado, procedeu-se o cálculo dos índices $\mathrm{CR}$ e $\mathrm{HH}$. No caso, considerou-se respectivamente: as quatro maiores, as seis maiores e as nove maiores empresas no mercado, para os anos de 
2000, 2006 e 2011, na sequência. A Tabela 4 mostra a variação do grau de concentração no segmento econômico/setorial no período considerado.

\begin{tabular}{cccc}
\multicolumn{5}{l}{ Tabela 4 - Índices de concentração no mercado de papel tissue } \\
\hline Índice (\%) & 2000 & 2006 & 2011 \\
\hline $\mathbf{C R}_{4}$ & 54,32 & 49,06 & 39,70 \\
$\mathbf{C R}_{\mathbf{6}}$ & 62,12 & 56,78 & 49,60 \\
$\mathbf{C R}_{9}$ & 69,28 & 64,86 & 58,80 \\
$\mathbf{H H}$ & 9,14 & 7,26 & 4,83 \\
\hline
\end{tabular}

Como é possível observar nos dados da tabela anterior, os valores dos índices de concentração demonstraram significativa redução ao longo do período considerado, notadamente no ciclo 2006-2011. Essa redução demonstra uma melhor distribuição do mercado, reflexo de uma maior competição entre as empresas. O índice $\mathrm{HH}$ acompanhou a tendência do índice $\mathrm{CR}$, passando de $\mathrm{HH}=7,26 \%$ em 2006 para $\mathrm{HH}=4,83 \%$ em 2011. Isto significa uma diminuição na concentração econômica

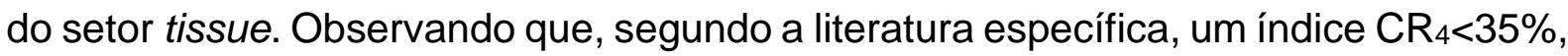
sugere ausência de concentração de mercado.

b) Barreiras à entrada: diz respeito aos obstáculos existentes para novas empresas quando elas decidem se lançar no mercado. Segundo Hause (1977), são dificuldades e empecilhos enfrentados por novos entrantes no negócio e mercado. Empresas já estabelecidas no mercado possuem vantagens em comparação com empresas potenciais entrantes (PORTER, 1991; 2005). Uma das maiores barreiras de entrada de novas empresas no setor consiste no alto investimento inicial de implantação do negócio (PEHRSSON, 2009). Outros tipos de barreiras à entrada são as barreiras fiscais, tributárias, de capital inicial, tecnologia, localização e espaço, compra, montagem e operação de maquinário e barreiras associadas à mão de obra, como treinamento (VITAL, 2008).

c) Diferenciação do produto: refere-se à variedade de formas e tipos de produtos que o mercado pode oferecer (PORTER, 1991). O mercado dos papéis tissue pode ser dividido em duas linhas de produtos bem diferenciadas: - At home, ou mercado das famílias, onde os produtos são usados no recesso dos lares - 
concorrência centrada em inovação e estabelecer uma marca; - Away from home, que atende o mercado institucional/empresarial, incluindo bares, restaurantes, hotéis, hospitais, unidades industriais, linhas aéreas - concorrência centrada em preços e relações comerciais longas. No que diz respeito aos papéis sanitários, a linhas principais de produtos são as seguintes: folha simples (boa ou alta qualidade), folha dupla e o papel higiênico comum.

\subsection{Conduta}

a) Propaganda: A estratégia de propaganda no segmento de papéis tissue no país é muito pouco utilizada. Um dos motivos para isso é o fato de se tratar de um produto de necessidade básica. Este pode ser um fator a ser explorado por novas empresas e empresas menores em termos de investimento.

b) Pesquisa e Desenvolvimento (P\&D): por se tratar de um mercado de concorrência acirrada, de grande ascensão da base industrial, os investimentos em P\&D são de extrema importância para o segmento tissue. $O$ fato de parcela significativa do mercado optar pela compra de um papel de melhor qualidade, no caso Folha Dupla, em substituição ao tipo Folha Simples, impõe um desafio de conjugar preço e qualidade para melhor atender aos consumidores através de novas tecnologias de produção.

Uma tendência de P\&D no segmento tissue é o estudo de compostos adicionados às fibras do processo, como por exemplo, a tecnologia dos plastificantes, incorporado na formulação, esse ingrediente provoca alteração da reologia química de Coating (revestimento), resultando em aumento do nível de umectação do filme formado. Permite assim, atender às necessidades particulares de cada máquina e proporciona maior produtividade e qualidade (O PAPEL, 2014).

Investimentos em inovação e sustentabilidade também tem sido destaque no setor. Um bom exemplo é a utilização e processamento de palha da cana-de-açúcar como insumos para produção de alguns tipos de papéis e embalagens. Uma fábrica pioneira que utilizará esse tipo de insumo foi inaugurada recentemente no interior paulista, na cidade de Lençóis Paulista. A produção inicial será de $25 \%$ do total da capacidade produtiva, com perspectivas de fabricação de diversos tipos de 
embalagens, além de papeis kraft e tissue (como papel higiênico e papel toalha). A pesquisa para se chegar ao processo que transforma a palha da cana-de-açúcar em pasta mecânica celulósica, matéria-prima 100\% sustentável durou cerca de seis anos. Tecnicamente, esse tipo de tecnologia propicia ganhos no processo produtivo, pois a pasta é livre de impurezas e não apresenta perda de matéria prima como ocorre com outros processos já existentes no mercado. Além de não incorrer em custo de descarte do resíduo proveniente da reciclagem, proporciona um ganho em termos de responsabilidade social, em função da escolha de uma matéria prima ambientalmente sustentável (PORTAL G1, 2017).

c) Custo, preço e tecnologia: Esse elemento representa um trinômio intrincado e autodependente para as vantagens competitivas. Para os produtos do setor, o preço também não é de fácil determinação. O preço não é função direta apenas do custo do produto, sofre influência de muitos outros fatores externos, como demanda do mercado, poder de barganha das empresas atuantes, diferenciação, qualidade e disponibilidade de um produto e matérias primas, tributação, taxas, entre outros fatores. O preço do produto depende muito do poder da imagem da marca, da diferenciação do produto e também da negociação entre vendedor/comprador.

Apesar de não haver teoricamente uma relação direta entre custo e preço, na prática eles estão intimamente vinculados e são a variável mais observada e controlada no processo produtivo (COSTA e GARCIAS, 2009). O principal componente do custo do papel tissue é a fibra, que representa $58 \%$ do total, seguida de mão de obra (12\%), combustível (9\%) e eletricidade (8\%) (VIDAL e HORA, 2013).

Importante ressaltar, porém, que os custos também podem variar significativamente entre as regiões de produção; de acordo com o processo produtivo escolhido, como por exemplo, as tecnologias Through Air Drying (TAD), Advanced Tissue Molding System (ATMOS); do tipo de fibra utilizado (baixa ou alta qualidade); entre outros fatores.

Nesse ponto, o Brasil se destaca por ser o maior produtor de celulose, atendendo ao seu mercado interno e exportando mais da metade da sua produção. Diferentemente de outros itens, o custo de fabricação de tissue no Brasil é muito menor do que o de outros países, devido a vantagens comparativas estáticas, que são clima, solo e nível de insolação no território brasileiro. Tais características fazem 
com que as árvores aqui tenham um tempo de crescimento e corte muito menor do que em outros países, o que permite um ciclo de produção mais rápido. Entretanto, devido às condições de demanda, a maior parte da produção nacional é exportada, o que é um fator de equilíbrio do preço da fibra, que é cotada em dólar.

d) Aquisições e fusões: A aquisição se trata da compra, ou seja, posse de uma empresa por outra. Por meio de fusões, corporações se integram para se fortalecer e enfrentar a concorrência. Logo, em um setor de baixa concentração, competitivo e lucrativo, essa é uma estratégia corporativa comum. Como ocorreu em 2009, quando a chilena CMPC comprou a empresa brasileira Melhoramentos, aumentando seu mercado e poder no mercado latino.

\subsection{Desempenho}

Os indicadores de desempenho avaliados para a indústria de papel tissue foram o crescimento do mercado; o crescimento interno de vendas e as perspectivas para este mercado, que foram considerados em conjunto por estarem diretamente vinculados entre si.

Segundo dados da BRACELPA (2014), o mercado de tissue no Brasil tem se tornado cada vez mais produtivo, o país é seu maior produtor na América Latina, atendendo a $32 \%$ do mercado da região. O México fica em $2^{\circ}$ lugar com $29 \%$ de participação.

Desde 2000, o volume quase dobrou, e as empresas continuam gerando um crescimento contínuo, mesmo frente a um cenário de instabilidade econômica nos últimos anos. Entre os tipos de papel, o consumo de tissue fica atrás apenas da produção de papéis para embalagens e de imprimir/escrever.

Como pode ser observado na Tabela 5 e na Figura 4, houve um significativo aumento no consumo do papel do tipo Folha Dupla, que saltou de 98.646 toneladas produzidas em 2006, para cerca de 300.000 toneladas em 2011, ultrapassando o consumo do tipo Folha Simples Boa Qualidade (FSBQ), passando a ocupar o segundo lugar entre os tipos mais vendidos, atrás apenas do tipo Folha Simples Alta Qualidade (FSAQ). 
Tabela 5 - Produção por tipo de papel tissue (ton/ano)

\begin{tabular}{lrrr}
\hline Tipo & $\mathbf{2 0 0 0}$ & $\mathbf{2 0 0 6}$ & $\mathbf{2 0 1 1}$ \\
\hline Folha Simples Alta Qualidade (FSAQ) & 192.700 & 307.618 & \multicolumn{1}{c}{485.980} \\
Folha Dupla (FD) & 63.378 & 98.646 & $299.860^{*}$ \\
Folha Simples Boa Qualidade (FSBQ) & 186.937 & 151.028 & 186.120 \\
Toalha de mão & 31.959 & 41.516 & 181.984 \\
Higiênico Popular & 61.769 & 117.581 & 62.040 \\
Guardanapo & 21.869 & 36.581 & 37.224 \\
Lenço & 2.338 & 2.979 & 4.136 \\
\hline
\end{tabular}

Fonte: Adaptado de BRACELPA (2014)

Como mostrado na Figura 4, o consumo do papel folha simples BQ sofreu oscilações entre crescimento, queda e crescimento no período. Na média, verifica-se uma tendência de diminuição no consumo de papéis folhas simples e aumento no consumo de folhas duplas.

Em 2006, os papeis de folha dupla correspondiam a apenas $16 \%$ do total, saltando para 28\% em 2012. Entre 2009 e 2012, a linha premium cresceu 17\%, enquanto a linha simples subiu apenas $1 \%$ nesse mesmo período.

Figura 4 - Crescimento do mercado por tipo de papel tissue no Brasil (1996-2012)


Fonte: Baseado em Pöyry (2015; 2017); Bastos e Souza (2016)

Nos últimos anos, estratégias de diferenciação do produto e do processo foram adotadas pelas empresas, inovações foram introduzidas, como no caso dos papeis sanitários, por exemplo, através da incorporação de perfume, cores e texturas variadas. 
Apesar do cenário de crise nos últimos três anos, com PIB estagnado em 2014 (0,1\%), agravado pelo colapso de -3,8\% em 2015 (segundo o IBGE), o Brasil passou a apresentar sinais de melhora em 2016, e há indícios de o pior já passou (IBA, 2016). Porém, mesmo com resultados positivos registrados pelos fornecedores do segmento tissue, pode-se dizer que há um otimismo moderado por parte dos empresários do setor industrial de celulose e papel (MARTIN, 2015; FARINHA e SILVA et al. 2016).

De forma geral, a perspectiva para o setor é que a produção permaneça aquecida, crescendo a taxas anuais de $4 \%$ até 2020 , superando os $2,5 \%$ registrados entre 2000 e 2015 (FARINHA e SILVA et al., 2016). Essa expectativa de crescimento é explicada pela tendência de melhoria das condições de higiene das pessoas e pelo aumento do nível de vida, com necessidade de investimentos para tirar muitas famílias que ainda vivem abaixo da chamada linha da pobreza. A tendência observada de mudança no perfil de consumo da população espera-se que seja acentuada nos próximos anos.

\section{CONCLUSÕES}

Este trabalho teve o objetivo de fazer uma apresentação e análise do mercado tissue no Brasil, adotando-se os fundamentos e a estrutura analítica do modelo ECD. Para isso foram utilizados dados secundários, pesquisas e dados de mercado. Como apresentado no decorrer do texto, o segmento tem se mostrado competitivo e com mercado distribuído, com concentração apenas geográfica dos fabricantes, localizando-se próximos aos maiores centros consumidores.

Apesar da subjetividade de modelos interpretativos por apresentarem lacunas e limitações inerentes à simplificação da realidade, o modelo ECD se mostrou adequado e plenamente satisfatório com a abordagem dinâmica adotada. A análise dos fatores estrutura, conduta e desempenho e de variáveis endógenas principais do modelo associados às considerações sobre o nível de concentração no mercado, em conjunto com aspectos exógenos para identificação de tendências e desafios do mercado, permitiram traçar um cenário sistêmico qualitativo e quantitativo do setor. Considera-se essa como a contribuição teórica principal do trabalho, que o coloca em linha com o estado da arte de estudos sobre organização industrial e dinâmica competitiva. 
Quanto aos objetivos específicos do trabalho, em relação à estrutura, como foi mostrado através da aplicação dos índices Razão de Concentração (RC) e HerfindahlHirschman $(\mathrm{HH})$, o grau de concentração do mercado do segmento tissue é bastante baixo, e tem se reduzido nos últimos anos. Como visto na Tabela 3, em 2000, o índice $\mathrm{HH}$ foi de $9,14 \%$, um percentual que mostra um mercado bem distribuído. A tendência verificada foi de queda, passando de um $\mathrm{HH}=7,26$, em 2006, até chegar a um $\mathrm{HH}=4,84 \%$, em 2011. Esses números mostram uma desconcentração bastante acentuada no mercado, correspondendo a cerca de $50 \%$ no período.

Essa tendência estrutural do segmento se reflete em um tipo de conduta e estratégias de competição direta e aberta, resultando em um mercado de acirrada concorrência, caracterizado, por um lado, em forte pressão por investimentos em novas tecnologias de produto e de processo; e por outro, a necessidade de redução de custos totais de fabricação e logística na cadeia de suprimentos. Outro desafio ao crescimento nos próximos anos se refere aos altos custos de energia para as indústrias.

Como consequência dessa estrutura, empresas que não conseguem estabelecer altos padrões de competitividade e sustentabilidade tendem a se tornar alvo de ofertas de aquisição por concorrentes mais fortes, principalmente os grandes grupos do setor. Existe uma forte tendência de entrada de novos competidores estrangeiros, o que tem sido uma ameaça às empresas nacionais. Nesse sentido, estratégias de fusão e incorporações para obtenção de ganhos de escala, redução de custos de fabricação e de logística através de maior integração na cadeia logística podem levar, no médio e longo prazo, a um aumento da concentração no setor.

No segmento tissue, outro fator que também merece ser mencionado é o poder dos varejistas, que não pode ser negligenciado, pois condiciona o padrão de conduta e as estratégias nos canais de distribuição, como por exemplo, o fortalecimento de marcas, com investimentos em marketing e propaganda, especialmente em mercados de menor consumo, porém com alto potencial de crescimento sustentável.

Quanto ao desempenho geral do segmento, o mercado tissue tem se mostrado bastante promissor. Como as maiores fábricas se localizam próximas aos grandes centros de consumo, os principais resultados são dependentes do crescimento nestes mercados. Entre 2000 e 2015, o segmento apresentou uma taxa de 3,2\% de crescimento médio anual, acima da média do setor, que foi de $2,5 \%$. 
Em relação ao desempenho por tipo de linha de produto, como mostrado na Figura 4, o maior destaque foi o crescimento de $17 \%$ no consumo do papel do tipo folha dupla, observado entre os anos de 2009 a 2012, alcançando a liderança entre os tipos mais consumidos, ultrapassando o consumo do papel folha simples, que apresentou um acréscimo no consumo de apenas $1 \%$ no mesmo período.

Como não houve um aumento na demanda geral que justificasse a discrepância mencionada, a hipótese mais provável é que tenha ocorrido um processo de migração do consumo de um tipo de papel de menor qualidade para outro de melhor qualidade, o que pode ser explicado pelo aumento gradativo do poder aquisitivo do consumidor de baixa renda no período. Apesar da estagnação da economia em 2014, e da queda brutal do PIB do país em 2015, devido à forte resiliência do setor, essa tendência provavelmente tenha sido apenas postergada. Essa é uma questão relevante para investigação em pesquisas futuras.

\section{REFERÊNCIAS}

ALBINO, A. et al. Aplicação do modelo analítico da cadeia de valor na análise da estratificação competitiva em um APL. Revista Produção Online, Florianópolis, v. 11, n. 1, p. 263-287, mar. 2011. ISSN 16761901. Disponível em: <https://www.producaoonline.org.br/rpo/article/view/856>. Acesso em: 26 fev. 2017. http://dx.doi.org/10.14488/1676-1901.v11i1.856.

BAIN, J. Industrial organization. 2.ed. New York: John Wiley \& Sons. 1968.

BASTOS, S. L.; SOUZA, S. D. C. Aplicação do Modelo ECD para Análise do Mercado e dos Índices CR e HH para Avaliação do Nível de Concentração no Segmento de Papéis Tissue no Brasil. In: ENCONTRO NACIONAL DE ENGENHARIA DE PRODUÇÃO,36., 2016.

Anais.... João Pessoa/PB, Brasil, out 2016. Rio de Janeiro: ABEPRO, 2016.

BRACELPA. Associação brasileira de celulose e papel. Relatório setorial, 2013.

CARLTON B.; PERLOFF, J. Modern industrial organization. Harper Collins, 1994.

CHEN, $\mathrm{H}$. International performance of multinationals: a hybrid model. Journal of World Business, v. 34, n. 2, summer, p. 157-170, 1999. https://doi.org/10.1016/S1090$\underline{\text { 9516(99)00014-0 }}$

CHURCH, J.; WARE, R. Industrial organization: a strategic approach, New York, USA, McGraw-Hill, 2000.

COSTA, F.; GARCIAS, P. M. Concentração de mercado e desempenho das indústrias brasileiras de papel e celulose - recorrendo à modelagem de Fleuriet para analisar 0 paradigma ECD. Revista de Contabilidade e Organizações - FEARP/USP, v. 3, n. 6, p. 143 - 163, maio/ago. 2009. http://dx.doi.org/10.11606/rco.v3i6.34745 
DAI, J.; CANTOR, D.; MONTABON, F. Examining corporate environmental proactivity and operational performance: A strategy-structure-capabilities-performance perspective within a green context. International Journal of Production Economics. v. 193, p. 272-280, nov, 2017.https://doi.org/10.1016/j.ijpe.2017.07.023

FARINHA e SILVA, C. A; BUENO, J. M.; NEVES, M. R. A Indústria de celulose e papel no brasil na primeira década do século XXI : a indústria de celulose e papel no Brasil. Guia ABTCP - Fornecedores \& Fabricantes - Celulose e Papel, 2015.

FARINHA e SILVA, C. A; BUENO, J. M.; NEVES, M. R. A indústria de celulose e papel no Brasil. A Indústria de Celulose e Papel no Brasil. Guia ABTCP - Fornecedores \& Fabricantes - Celulose e Papel, 2016.

GRANT, R. The Resource-Based Theory of Competitive Advantage: Implications for Strategy Formulation. California Management Review, v. 33, n. 3, spring, p. 114-135, 1991. https://doi.org/10.2307/41166664

HAUSE J. C. The Measurement of concentrated industrial structure and the size distribution of firms. Annals of Economic and Social Measurement, v. 6, n. 1, p. 73-107, 1977. Disponível em: http://www.nber.org/chapters/c10503.pdf Acesso em: 20 nov 2015.

HENDERSON, B. As origens da estratégica. Em: MONTGOMERY, C. \& PORTER, M. Estratégia. Campus, Rio de Janeiro. 1998.

GAVETTI, G.; GREVE, H.; LEVINTHAL, D.; OCASIO, W. The Behavioral Theory of the Firm: Assessment and Prospects. Academy of Management Annals, v. 6, n.1, p.1-40, 2012. https://doi.org/10.1080/19416520.2012.656841

IBA. Instituto Brasileira de Árvores. Relatório anual. 2015.

IBA. Instituto Brasileira de Árvores. Relatório anual. 2016.

KADIYALI, V.; SUDHIR, K.; RAO, V. Structural analysis of competitive behavior: New empirical industrial organization methods in marketing. International Journal of Research in Marketing, v. 18, n. 1, p. 161-186, 2001. https://doi.org/10.1016/S0167-8116(01)00031-3

LIPCZYINSKI, J., WILSON, J., GODDARD, J. Industrial organization: Competition, Strategy, Policy. Harlow, UK: Prentice Hall, 2009.

MARTIN, C. Segmento tissue segue aquecido e amplia participação na produção total de papéis no País, Revista O Papel, S. Paulo, jun, 2015.

MASON, E. S. Price Production Policies of Large-Scale Enterprise. American Economic Review, v. 29, n.1, p. 64-71, mar. 1939.

MCAULIFFE, R. E. Herfindahl-Hirschman Index. Wiley Encyclopedia of Management. v. 8, n. 1, 2014.

MILANEZ, A.F.; HOST, A.M. Antena Tecnológica: Tissue Paper, Relatório Técnico P\&D306/05, Companhia Suzano de Papel e Celulose, 2005. Disponível em: https://www.academia.edu/27474834/Tissue Paper Revis\%C3\%A3o tecnol\%C3\%B3gica ?auto=download Acesso: dez 2016. 
NAWROCKI, D.; CARTER, W. Industry competitiveness using Herfindahl and entropy concentration indices with firm market capitalization data. Applied Economics, v. 42, n. 22 , p. 2855-2863, 2009. https://doi.org/10.1080/00036840801964666

O PAPEL. Mercado em Expansão - abr 2014.

O PAPEL (a). Segmento de Tissue dribla baixo desempenho da economia. Abr 2015.

O PAPEL (b). Uma breve análise sobre o mercado de aparas e tissue. Out 2015.

PEHRSSON, A. Barriers to entry and market strategy: a literature review and a proposed model, European Business Review, v. 21, n.1, pp. 64-77, 2009. https://doi.org/10.1108/09555340910925184

PORTAL G1 - Reportagem em vídeo. Disponível em: http://g1.globo.com/sp/baurumarilia/tem-noticias-2edicao/videos/v/lencois-paulista-inova-com-producao-da-materiaprima-para-o-papel-a-partir-da-palha/5635282/ Acesso em: 22 fev. 2017.

PORTER, M.E. Towards a dynamic theory of strategy. Strategic Management Journal. v.12, n. 52, winter, p. 95-117, 1991. https://doi.org/10.1002/smj.4250121008

PORTER, M.E. Estratégia competitiva. 1. ed. Rio de Janeiro: Campus/Elsevier, 2005.

PÖYRY. International Consulting and Engineering Company. Expanding Geographic Reach; gaining new market share in paper. Industry Report - Pulp and Paper, 2015.

PÖYRY. International Consulting and Engineering Company. Consumo de papeis sanitários no Brasil cresce 38\% em uma década mostra-Pÿry. Notícias. 02 Fev 2017. Disponível em: http://www.poyry.com.br/not\%C3\%ADcias/consumo-de-papeis-sanitarios-no-brasil-cresce38-em-uma-decada-mostra-poyry Acesso em: 15 fev. 2017.

RIBEIRO, A. C. S.; SANTOS, B. S.; SOUZA, S. D. C.. In: ENCONTRO NACIONAL DE ENGENHARIA DE PRODUÇÃO (ENEGEP), 33., 2013. Anais... Salvador/BA, Brasil, out 2013. Rio de Janeiro: Abepro, 2013.

SARAIVA, F.; CAPO, P. Papéis Tissue: Em busca de uma identificação necessária. Revista O Papel, São Paulo, v. 64, n. 3, p. 61-71, mar 2003.

SCHERER, F. M.; ROSS, D. Industrial market structure and economic performance. 3. ed. Chicago: Raud Mc Nally \& Co, 1990.

SOUZA, S. D. C.; ARICA, J. Mudança tecnológica e estratificação competitiva em um arranjo produtivo do setor ceramista. Prod, São Paulo, v. 16, n. 1, p. 8899, Apr. 2006. http://dx.doi.org/10.1590/S0103-65132006000100008.

SOUZA, S.D.C.; LOBO, P.E.; MANHÃES, C.H. Conjugação da curva de pareto com a matriz BCG para definição de estratégias de produto em duas unidades fast food. Revista Produção Online, Florianópolis, v. 10, n. 4, p. 818-836, nov. 2010. ISSN 16761901. http://dx.doi.org/10.14488/1676-1901.v10i4.483.

SOUZA, S.D.C. Dinâmica competitiva evolucionária. 1. ed. São Paulo: Blucher, 2011.

TISSUEONLINE. Entendendo o mercado brasileiro de tissue - parte la - tissueonline, disponível em: http://tissueonline.com.br/artigos/artigo 10 tissue.pdf 
VIDAL, A. C. F.; HORA, A. B. Panorama de mercado: papéis sanitários. Biblioteca digital BNDES - 2013.

WIRTH, M.O.; BLOCK, H. Industrial organization theory and media industry analysis. Journal of Media Economics, v. 8, n. 2, p. 15-26. 1995.

https://doi.org/10.1207/s15327736me0802 3

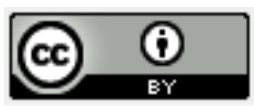

Artigo recebido em 27/02/2017 e aceito para publicação em 07/12/2017

DOI: http://dx.doi.org/10.14488/1676-1901.v18i1.2745 